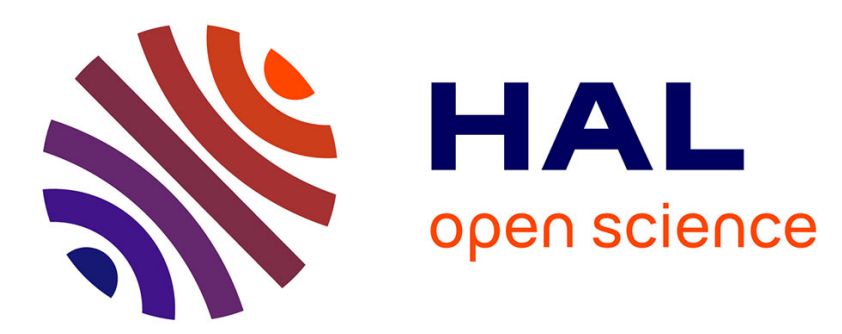

\title{
High strain rate out-of-plane compression of birch plywood from ambient to cryogenic temperatures
}

L. Caetano, Vincent Grolleau, B. Galpin, A. Penin, J.-D. Capdeville

\section{To cite this version:}

L. Caetano, Vincent Grolleau, B. Galpin, A. Penin, J.-D. Capdeville. High strain rate out-of-plane compression of birch plywood from ambient to cryogenic temperatures. Strain, 2018, 54 (2), pp.e12264. 10.1111/str.12264 . hal-03009395

\section{HAL Id: hal-03009395 \\ https://hal.science/hal-03009395}

Submitted on 17 Nov 2020

HAL is a multi-disciplinary open access archive for the deposit and dissemination of scientific research documents, whether they are published or not. The documents may come from teaching and research institutions in France or abroad, or from public or private research centers.
L'archive ouverte pluridisciplinaire HAL, est destinée au dépôt et à la diffusion de documents scientifiques de niveau recherche, publiés ou non, émanant des établissements d'enseignement et de recherche français ou étrangers, des laboratoires publics ou privés. 


\title{
High strain rate out-of-plane compression of birch plywood from ambient to cryogenic temperatures
}

\author{
Lydie Caetano ${ }^{1}$, Vincent Grolleau ${ }^{1}$, Bertrand Galpin ${ }^{1,2}$, Arnaud \\ Penin $^{1}$, and Jean-Damien Capdeville ${ }^{3}$ \\ ${ }^{1}$ Univ. Bretagne Sud, FRE CNRS 3744, IRDL, F-56100 Lorient, \\ France \\ ${ }^{2}$ Crec, Ecoles de Saint-Cyr Coëtquidan, F-56380 Guer, France \\ ${ }^{3}$ GTT, Gaztransport \& Technigaz, F-78470 \\ Saint-Rémy-lès-Chevreuse, France
}

December 7, 2017

\begin{abstract}
An extensive series of compression tests with birch plywood specimens are conducted in the out-of-plane direction. Various experimental conditions are tested with different temperatures and strain rates. To this end, a specially designed Split Hopkinson Pressure Bar protocol is defined and the specimen dimensions are validated from quasi-static EN789 standards experiments. Temperatures are ranging from ambient down to $-170^{\circ} \mathrm{C}$, while strain rates are increased from $0.004 / \mathrm{s}$ up to $700 / \mathrm{s}$. The analysis of the experimental results focuses on the hardening behaviour and the following densification regime at large strains. Evolution with temperature and strain rate of the four coefficients of the stress versus strain curve interpolation is discussed, and models are proposed.
\end{abstract}

\section{INTRODUCTION}

Applications for plywood range from the packaging of precious artworks to shipbuilding and pioneering aircraft engineering. When plywood board is part 
Caetano L, Grolleau V, Galpin B, Penin A, Capdeville J-D. High strain rate out-of-plane compression of birch plywood from ambient to cryogenic temperatures. Strain. 2018. https://doi.org/10.1111/str.12264

of a structure, usually only its in-plane mechanical properties need to be known to determine the structural response. But when plywood is used for packaging, the contact behaviour between the plywood and transported goods or external projectiles is of primary interest. For example, Toson and Adalian [4, 29] studied the behaviour of balsa wood used to transport nuclear material, focusing on the strain rate sensitivity and cushioning properties of the balsa wood at ambient temperature. In Liquefied Natural Gas shipping transport, the temperature of the LNG is about $-163^{\circ} \mathrm{C}$. Most of the insulation systems belong to the socalled membrane type [3], in which the insulation complex is composed of a metal membrane as a barrier (1.2 mm thick, 304 grade stainless steel), a plywood panel (12mm thick, cross-ply plywood made from 9 birch veneers birch wood), insulation foam (Reinforced PolyUrethane Foam), and a plywood panel glued to the inner hull. In this case, the plywood may be accidentally subjected to out-of-plane compression at cryogenic temperatures and high strain rates [2,11]. This example illustrates the industrial relevance to study the outof-plane behaviour of plywood under various experimental conditions of strain rates and temperatures.

A few studies have dealt with the cryogenic behaviour of wood materials, but most of them only deal with the in-plane properties of wood based materials or the properties along the clear wood fiber direction. One of the first studies was presented by Kollmann in 1941 [24]. His study was completed later by Boller in 1954 [8] for three species tested in compression perpendicular to the fiber with a $9 \%$ moisture content at room temperature, and at $-185^{\circ} \mathrm{C}$. Boller showed that the stress limiting the elastic domain at $-185^{\circ} \mathrm{C}$ was 2.25 to 3.5 times higher than that of room temperature. This reference is the only one cited in the review presented by Gerhards [18] in 1982 for cryogenic conditions. Recently, Arswendy et al. [5] studied the bending strength of Finnish birch plywood. The flexural properties of birch wood have been studied from ambient down to cryogenic temperature by Zhao [35]. Drake [13] studied glulam beams made of douglas wood, Ayrilmis [7] studied three wood-based panels. They proved that both the modulus of rupture and the modulus of elasticity along the fiber direction increased with decreasing temperature [5, 7, 13, 35].

The high strain rate of wood was discussed by Reid and Gibson [19, 25] who derived a so-called Rigid Perfectly-Plastic Locking model (RPPL). Bragov [9] used a $20 \mathrm{~mm}$ steel Split Hopkinson Pressure Bar (SHPB) apparatus for the axial and transverse compression of pine, birch and lime clear woods, derived shock adiabats for the wood samples, and produced compression test results for strain rates of 500/s and 1000/s. More recently, Widehammar [30] studied the influence of strain rate, moisture content and loading direction on the compression behaviour of clear spruce wood for various strain rates from quasi-static con- 
dition up to $1000 / \mathrm{s}$ using the SHPB apparatus and $12 \mathrm{~mm}$ side length cubic specimens. In order to adjust the specimen-bar impedance mismatch, Widehammar used $12 \mathrm{~mm}$ side-length squared cross-section bars, made of steel for axially loaded specimens and magnesium alloy for the other directions. This study clearly showed the huge influence of the strain rate on the radial compression behaviour of spruce wood, which was less visible in the transverse direction due to the early failure of the specimen when loaded in this direction. In the same way, Eisennacher [14] presented experimental results on crushing tests of spruce wood. They varied in orientation, loading rate and lateral constraint of the specimen. This study confirmed the strain rate sensitivity of the wood when compressed in the transversal or radial directions, and provided important results on the effect of lateral confinement.

To the best of our knowledge, no study has dealt with the combined effect of increasing the strain rate and decreasing the temperature on the compression behaviour of wood in a non-axial direction or plywood in the out-of-plane direction. In the present work, a $12 \mathrm{~mm}$ thick plywood made of 9 Finnish birch veneers is studied. Compression tests are performed under quasi-static and high strain rates at up to $700 / \mathrm{s}$, and for temperature ranging from ambient down to cryogenic temperatures of $-170^{\circ} \mathrm{C}$.

In the following section, the material of the study is presented and the experimental apparatus are described. Quasi-static and high strain rate experiments are presented in detail along with the analysis methodology of the tests and the validation of the specimen dimensions. Special attention is paid to the wave propagation during experiments in cryogenic conditions with a Split Hopkinson Pressure Bar system.

In the third section, experimental results are presented focusing on the hardening behaviour and the following densification regime at large strains. The stress versus strain curve is fitted via a linear and an exponential equation of the strain requiring the identification of four coefficients. The strain rate and temperature evolution of these coefficients is studied and a uniform model is proposed and identified.

\section{Material and experimental devices}

\subsection{Material}

The tested plywood is commercialised by the UPM company. UPM is the leading supplier of birch plywood for LNG carriers, with more than 200 references over the global fleet made up of 400 LNG carriers [3, 15, 23]. Plywood is a crucial structural material for the GTT NO-96 and MARKIII insulation sys- 
tems which are the most common systems employed. This marine plywood is a cross-ply laminate, made of arctic birch wood from Finland. The two external veneers are $1 \mathrm{~mm}$ thick, while the others are $1.4 \mathrm{~mm}$ thick. The standard thickness is $12 \mathrm{~mm}$, in this case it is composed of 9 veneers of birch wood glued with phenolic resin ref.PF1072 produced by Momentive company. The specimens are machined using a CNC milling machine. In order to guarantee a homogeneous moisture content of the specimens, at $7.5 \pm 0.5 \%$ Moisture Content, they are stored at least three days in a climatic chamber, at $23^{\circ} \mathrm{C}$ and $48 \%$ relative humidity before testing. Under these conditions, the measured density of the plywood is $670 \mathrm{~kg} / \mathrm{m}^{3}$.

\subsection{Quasi-static compression device}

Quasi-static apparatus design An Instron tensile machine equipped with a $50 \mathrm{kN}$ or a $500 \mathrm{kN}$ load cell is used depending on the maximum load to be reached during the test. The compression platens are made of EN 1.4057 (AISI 431) stainless steel. The upper platen is fixed while the lower one is spherically seated which allows for adjustments in alignment prior to each batch of experiments.

The EN 789 standard recommends a square cross-section side-length $45 \mathrm{~mm}$, and $70 \mathrm{~mm}$ length, for quasi-static tests at room temperature. But these dimensions are not compatible with high strain rate test recommendations presented in section 2.3. The optimisation of the high strain rate test led us to choose a single $28 \mathrm{~mm}$ diameter circular $L_{0=} 12 \mathrm{~mm}$ thick specimen. Since various quasistatic and high strain rate tests at room and cryogenic temperatures are involved, we chose to use the same specimen geometry regardless of the strain rate.

Tests are required at various sub-freezing temperatures that cause frosting and fogging of windows and lenses. As a consequence, the elongation and strain were obtained from the machine stroke. Digital image correlation is only used at room temperature for validation purposes.

Since the measurement of the machine stroke $\Delta L_{\text {stroke }}$ is used to calculate the specimen axial elongation $\Delta L$, it is necessary to perform a correction $\Delta L_{\text {stiffness }}$ of the stroke for the machine stiffness during the test. Thus, for each test series, a platen to platen test is performed, i.e. without any specimen [12]. The displacement versus load response of the testing system during the platen to platen test is recorded, and fitted using a third order polynomial up to a load value of $12.5 \mathrm{kN}$, and a linear function above $12.5 \mathrm{kN}$. The fitted function $\Delta L_{\text {stiffness }}(F)$ is used to correct the stroke at each load value $F$ using:

$$
\Delta L(F)=\Delta L_{\text {stroke }}(F)-\Delta L_{\text {stiffness }}(F)
$$


The stiffness correction procedure was validated at room temperature using $3 \mathrm{D}$ DIC measurements on the specimens for a $12 \mathrm{~mm}$ thick specimen and a stack of 3 to 5 glued specimens, for both circular and square geometries, following the EN789 recommendations. The discrepancy between the results was found to be lower than the standard uncertainty of the reference results using the EN789 geometry.

Once the corrected elongation $\Delta L$ is obtained, the engineering $\epsilon_{n}$ and true $\epsilon$ axial strains and engineering $\sigma_{n}$ and true $\sigma$ axial stresses are calculated:

$$
\begin{array}{r}
\epsilon(t)=\ln \left(1+\epsilon_{n}\right) \quad \text { with } \quad \epsilon_{n}=\frac{\Delta L}{L_{0}} \\
\sigma(t)=\frac{F}{S} \quad \text { and } \quad \sigma_{n}(t)=\frac{F}{S_{0}}
\end{array}
$$

Where $L_{0}$ is the initial thickness of the specimen and $S_{0}(S)$ is the initial (actual) cross-section of the specimen respectively.

For quasi-static tests, a constant crosshead velocity $v$ is used. For each quasistatic test, the reference strain rate is the rate of change of the engineering strain and reads as $\dot{\varepsilon}=\frac{v}{L_{0}}$. For example, in the case of the $L_{0}=12 \mathrm{~mm}$ thick specimens at a strain rate of $\dot{\varepsilon}=4.10^{-3} / \mathrm{s}$, the crosshead velocity is $v=0.048 \mathrm{~mm} / \mathrm{s}$.

Size specimen effect Furthermore, it is necessary to ensure that the specimen is of a size that reveals the global behaviour of the plywood. Thus, a Representative Volume Element (RVE) study is performed. The result (Fig.1) shows that specimen from 10 to $50 \mathrm{~mm}$ in diameter and from 12 to $36 \mathrm{~mm}$ in thickness have the same behaviour under a quasi-static strain rate.

Cryogenic conditions An environmental chamber was used for quasi-static tests at all temperatures (Fig,2).

The temperature is controlled using 2 thermocouples located on the lower platen and the chamber. A third $0.16 \mathrm{~mm}$ diameter type $\mathrm{K}$ thermocouple is inserted in the centre of the specimen, using a $10 \mathrm{~mm}$ long and $0.65 \mathrm{~mm}$ diameter radial hole drilled at mid-axial length. A control loop regulates the temperature using a remote valve and a liquid nitrogen sprinkler located on the top of the chamber. A fan is used in order to homogenize the temperature within the chamber, and special attention is paid to avoid any contact between the plywood and the liquid nitrogen [23]. The measured specimen temperature remain within $\pm 10^{\circ} \mathrm{C}$ of the prescribed temperatures during testing. 


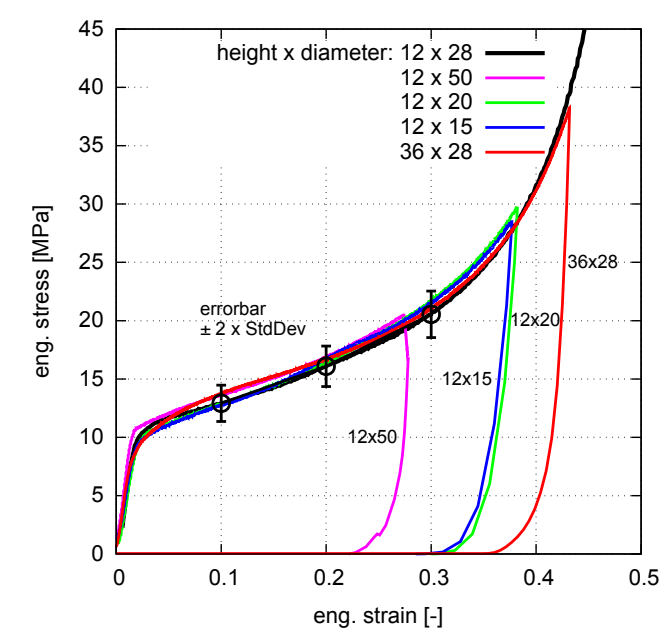

Figure 1: Engineering stress-strain curves for various specimen geometries at ambient temp., $8 \%$ moisture content, $4 \cdot 10^{-3} / \mathrm{s}$ strain rate. Error bars represent two standard deviation obtained from the repeatability study of the compression of $12 \mathrm{~mm}$ thick and $28 \mathrm{~mm}$ diameter specimens.

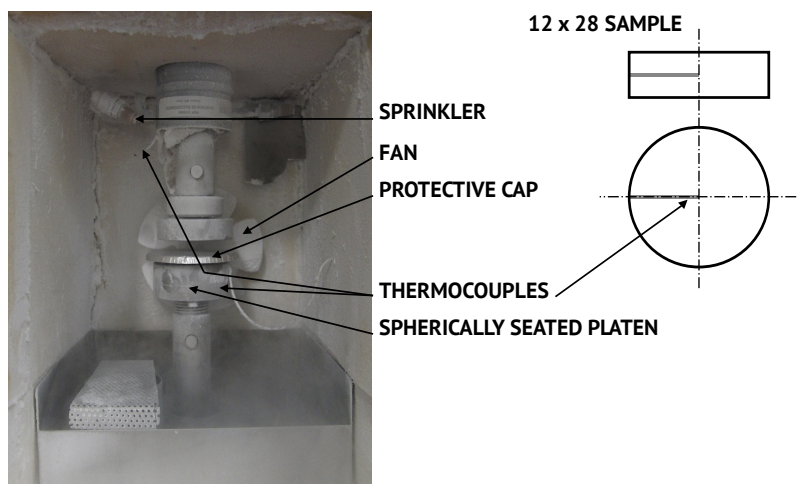

Figure 2: View of the climatic chamber used for quasi-static testing and design of the $12 \mathrm{~mm}$ thick and $28 \mathrm{~mm}$ diameter specimen equipped with a thermocouple located at mid axial length.

\subsection{Split Hopkinson pressure bar device}

SHPB device design A classical Split Hopkinson Pressure Bar (SHPB) or Kolsky compression bar apparatus comprising a striker, an input and an output bar is illustrated in Fig. 3, [27]. The specimen is sandwiched between the input and the output bars. The bars have the same circular cross-section and are made of the same material. In the following, we denote $L_{s}$ as the length of the striker, $E_{b}$ the Young's modulus of the bars, $S_{b}$ the cross-sectional area, and $C$ the celerity 
of sound.

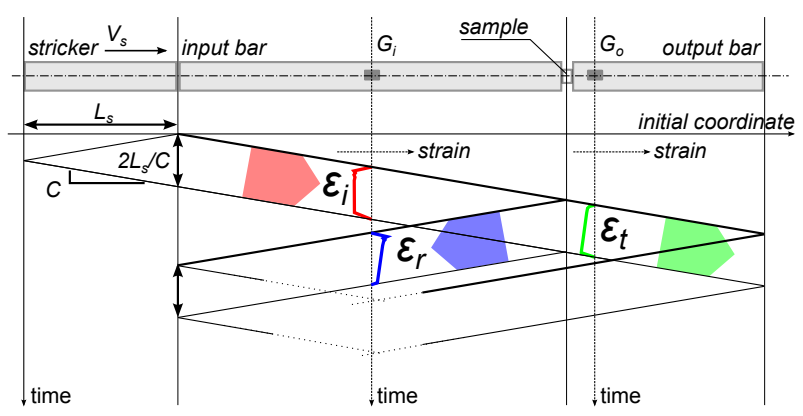

Figure 3: Space versus time representation of the wave propagation in the classical Split Hopkinson Pressure Bar experiment.

In the SHPB test, the striker is launched at an initial velocity $V_{s}$, while the other bars and the specimen are at rest. The impact generates an elastic compressive strain wave of theoretical duration $2 L_{s} / C$ and constant value of $-V_{s} /(2 C)$ that propagates along the striker and the input bar. When the later strain wave, referred to as the incident wave $\epsilon_{i}$, propagates to the interface between the input bar and the specimen, part of it is reflected backwards into the input bar due to impedance mismatch at the bar/specimen interface, and is referred to as the reflected wave $\epsilon_{r}$. The remaining part of the incident wave is transmitted into the specimen and gets reflected between the bar/specimen interfaces. These reflections gradually compress the specimen, and generate the so-called transmitted wave $\epsilon_{t}$ at the specimen/output bar interface that propagates into the output bar, and lead to the equilibrium of the specimen [10, 20, 27]. Both $\epsilon_{i}$ and $\epsilon_{r}$ are measured by the strain gage $G_{i}$ located at the middle of the input bar. The $\epsilon_{t}$ signal is measured by the strain gage $G_{o}$ located on the output bar. Fig. 3 shows typical time-resolved strains measurements. The striker and bar lengths are chosen to avoid any superimposition of the $\epsilon_{i}$, $\epsilon_{r}$ and $\epsilon_{t}$ signals. As the three waves are recorded along the bars, they must be shifted to specimen/bar interfaces using a procedure that accounts for geometric dispersion in order to allow for the exact calculation of loads $F$ and particle velocity $V$ at the specimen/bar interfaces. The wave shifting is performed numerically in the frequency domain after FFT of the signals [16]. For each frequency, the wave number is calculated numerically from the so-called frequency equation, the complete solution of the Pochhammer-Chree's longitudinal wave analysis, and presented by Zhao [33]. The recorded strain signals are post-processed with the software package DAVID proposed by Gary, [17].

In the case of elastic bars, input and output loads $F_{i}$ and $F_{o}$, input and output velocities $V_{i}$ and $V_{o}$ at the ends of the input and output bars are calculated from 
the shifted signals as follows:

$$
\begin{gathered}
F_{i}=-E_{b} \cdot S_{b} \cdot\left(\epsilon_{i}+\epsilon_{r}\right) \\
F_{o}=-E_{b} \cdot S_{b} \cdot\left(\epsilon_{t}\right) \\
V_{i}=-C \cdot\left(\epsilon_{i}-\epsilon_{r}\right) \\
V_{o}=-C \cdot\left(\epsilon_{t}\right)
\end{gathered}
$$

For a cylindrical specimen of initial length $L_{0}$, the nominal strain rate of compression $\dot{\varepsilon}_{n}$, with a positive value in compression for the sake of simplicity, is given by:

$$
\dot{\varepsilon}_{n}(t)=\frac{V_{i}-V_{o}}{L_{0}}=\frac{C}{L_{0}} \cdot\left(-\epsilon_{i}+\epsilon_{r}+\epsilon_{t}\right)
$$

and the true strain $\varepsilon$ can be calculated from:

$$
\varepsilon(t)=\ln \left(1+\int_{0}^{t} \dot{\varepsilon}(\tau) d \tau\right)
$$

Note that the true stress $\sigma$ within the specimen may be calculated either from the input force or from the output force:

$$
\sigma_{i}(t)=\frac{F_{i}}{S} \quad \text { or } \quad \sigma_{o}(t)=\frac{F_{o}}{S}=\frac{E_{b} \cdot S_{b} \cdot \varepsilon_{t}}{S}
$$

The input load $F_{i}$ and the velocity $V_{i}$ are calculated from the sum Eq. 4 and the difference Eq. 6 between the incident $\epsilon_{i}$ and the reflected signals $\epsilon_{r}$ respectively. These two strains are recorded using the same gages, thus the uncertainty of the evaluation of $F_{i}$ and $V_{i}$ depends on the balance between $\epsilon_{i}$ and $\epsilon_{r}$, and the best compromise is obtained for a strain ratio of $\frac{\epsilon_{r}}{\epsilon_{i}}=\frac{-1}{2}$. The output load $F_{o}$ and the velocity $V_{o}$ are proportional to the transmitted strain $\varepsilon_{t}$, thus the optimization of the signal to noise ratio leads to the maximization of the transmitted strain $\varepsilon_{t}$ up to the elastic limit of the bar.

In order to limit the wave dispersion effect, it is recommended to use slender bars [10,21]. Additionally, wood is a non-homogeneous material, and it is recommended to use large specimens [1,26]. We thus selected $30 \mathrm{~mm}$ diameter and $3 \mathrm{~m}$ long 7075 aluminium bars with a $1.20 \mathrm{~m}$ long projectile; and a diameter of $28 \mathrm{~mm}$ for the specimens. If we assume a load equilibrium between the two interfaces of the specimen, and an optimal strain ratio, then Eq.8 leads to an initial velocity of the striker of about $12 \mathrm{~m} / \mathrm{s}$. 
Cryogenic conditions For cryogenic tests, we decided to keep the bars at room temperature, and in order to avoid any warm-up of the specimen when in contact with the bars, the specimen is cooled-down along with two $40 \mathrm{~mm}$ long $30 \mathrm{~mm}$ diameter aluminium extension rods placed on each face of the specimen, as shown in Fig.4. Prior to the test, the specimen and the two extension rods are placed in a climatic chamber, see Fig. 4. This specially designed chamber is made of a polyurethane foam $\mathrm{V}$-holder, and a foam cap. The axis of the chamber is coaxial to the bars axis and can move freely along this axis. A sprinkler cools-down the specimen and the extension rods with a temperature regulated nitrogen gas. During the tests, the temperatures of the injected nitrogen, the specimen and the extension rods are recorded. The specimen temperature variations are found to remain within $\pm 5^{\circ} \mathrm{C}$.

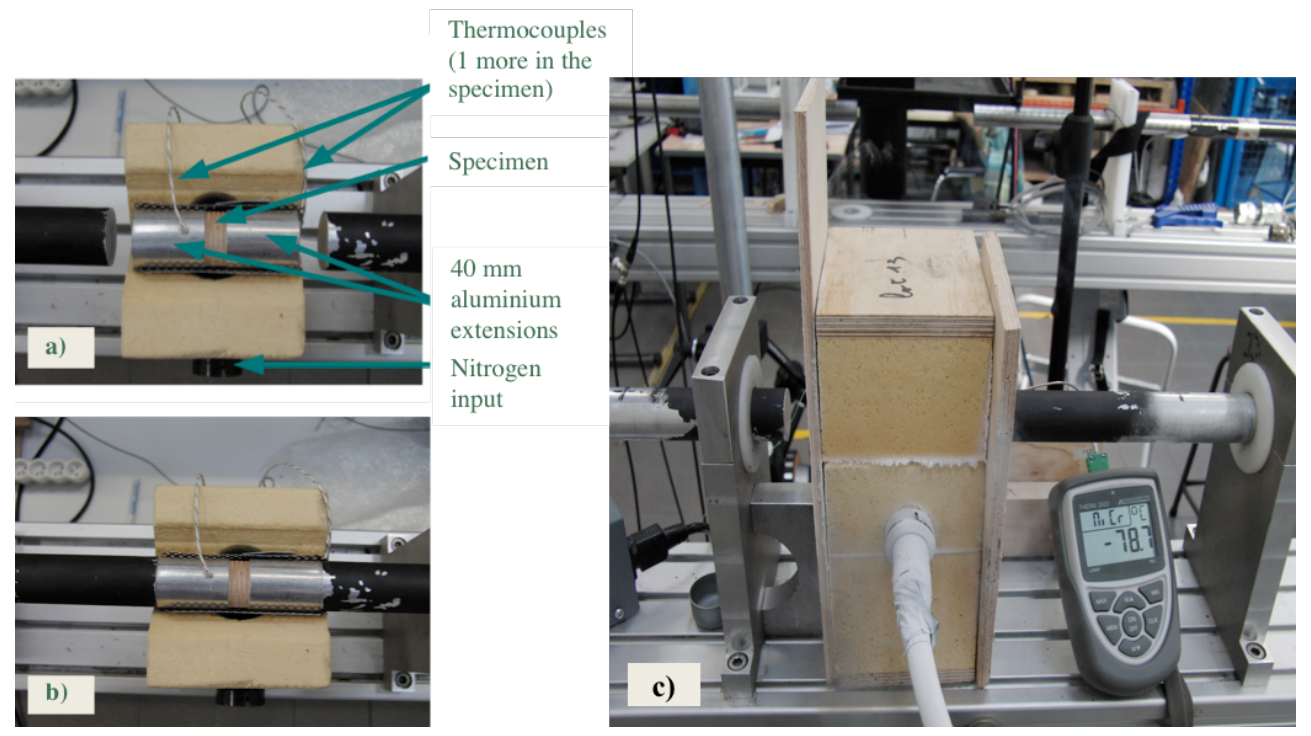

Figure 4: Top view of the V-holder polyurethane foam, the bars, the extensions and the specimen (a) before the test and (b) when the bars are in contact with the extensions. Side view of the climatic chamber and the bars (c).

SHPB apparatus validation Preliminary sets of SHPB compression tests are performed in order to validate the SHPB apparatus in the case of cryogenic tests of plywood. A first compression test of a birch plywood, $12 \mathrm{~mm}$ thick, $28 \mathrm{~mm}$ in diameter, at room temperature, is performed with an initial striker velocity $V_{s}=11 \mathrm{~m} / \mathrm{s}$. The strain ratio was found to be in the range $[-0.7 ;-0.4]$, close to the ideal ratio: $\frac{\epsilon_{r}}{\epsilon_{i}}=\frac{-1}{2}$.

As presented above in Eq, 4 and 5, the load can be measured independently on each of the bar/specimen interfaces. Fig.5 shows the evolution of each load 
versus time for a room temperature test, without extensions. The equilibrium is not obtained immediately, but as long as the difference between the two loads is lower than $3 \%$, the specimen here is considered being in static equilibrium, and the corresponding time interval is referred to as the SHPB equilibrium time interval.

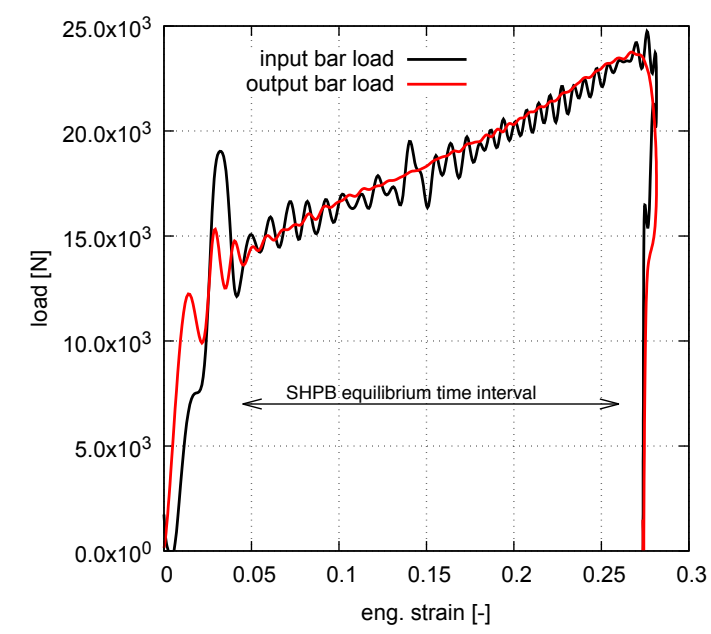

Figure 5: Input and output loads versus time during the SHPB test at room temperature of a $12 \mathrm{~mm}$ thick $28 \mathrm{~mm}$ diameter, $8 \%$ moisture content birch plywood specimen.

The equilibrium of the specimen may be affected by the insertion of the two cold extensions. It is thus necessary to evaluate their influence on the measured signals by a set of so-called Bar-Bar tests, without any specimen, and at various temperatures. In the absence of specimen, if the input and the output bars have the same characteristics, the theoretical reflected wave is null. If the extensions affect the propagation of the waves, then the reflected wave will be modified. Fig. 6 shows the results obtained for SHPB Bar-Bar experiments without and with extensions at room temperature, and with extensions at cryogenic temperature $-180^{\circ} \mathrm{C}$. For all the experimental conditions, during the SHPB equilibrium time interval, the reflected signal remains lower than a few percent of the incident signal, and it can be concluded that the extensions have no significant influence on the measurements, except the modification of the gage to interface distance to be taken into account for the wave shifting.

Finally, the strain rate, the nominal strain and the nominal stress can be calculated from Eq.8, Eq.9 and Eq.10. The result is plotted in Fig.7. During the SHPB equilibrium time interval, the strain rate is almost constant at about $700 / s$. As a consequence the strain versus time evolution is quasi linear with a final value of about $27 \%$. The stress shows only very small oscillations. 


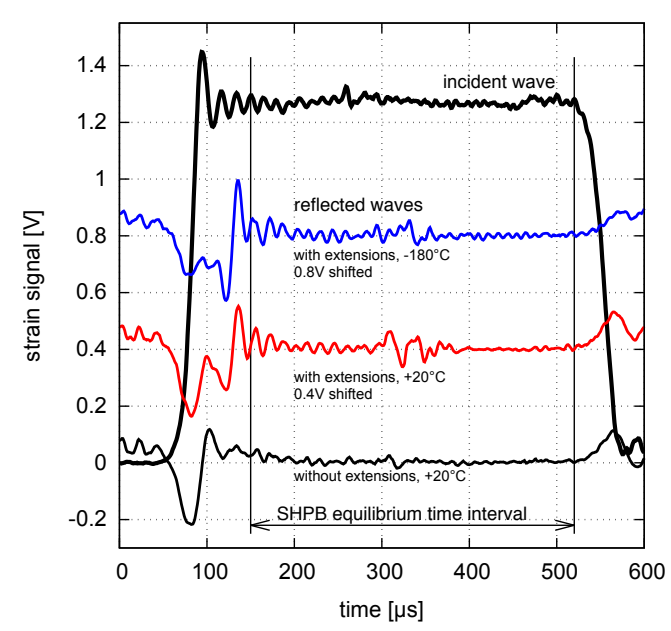

Figure 6: Incident and reflected signals obtained during Bar-Bar SHPB tests without projection at room temperature, with projections at room temperature $(0.4 \mathrm{~V}$ vertically shifted $)$, with projections at cryogenic temperature $-180^{\circ} \mathrm{C}$ ( $0.8 \mathrm{~V}$ vertically shifted).

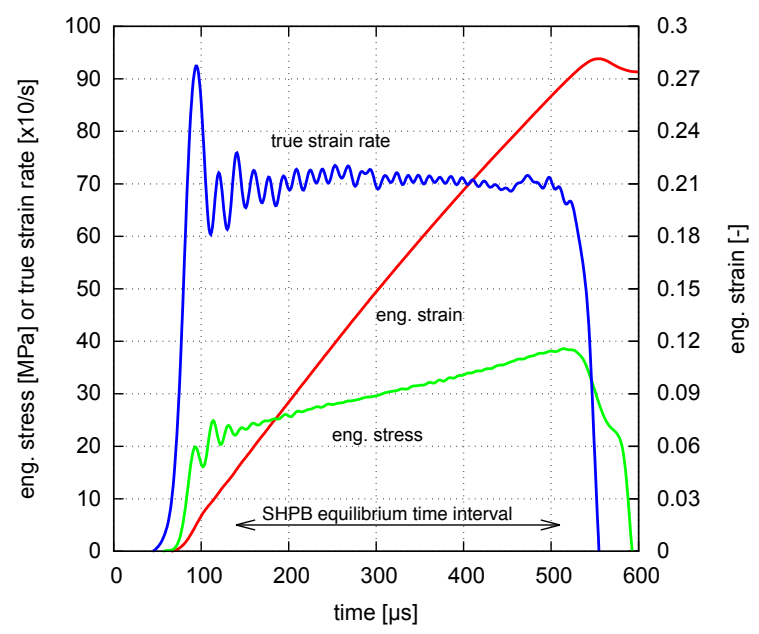

Figure 7: Time evolution of the strain rate, the nominal strain and the nominal stress during the SHPB test of a $12 \mathrm{~mm}$ thick plywood specimen at room temperature.

\subsection{Design experiments}

A summary of the experimental conditions is given in Table 1 . At least five repetitions are performed for each condition. Tests are performed without lubrication at sample interfaces. 
Table 1: List of the tested experimental conditions for out-of-plane compression of $12 \mathrm{~mm}$ thick and $8 \%$ moisture content birch plywood.

\begin{tabular}{|c|c|c|c|c|c|} 
Strain rate $[/ s]$ & $4.10^{-4}$ & $\underline{4.10^{-3}}$ & $4.10^{-2}$ & $4.10^{-1}$ & $\underline{700 .}$ \\
\hline Temp. $\left[{ }^{\circ} \mathrm{C}\right]$ & +23. & $\underline{+23 .}$ & +23. & +23. & $\underline{+23 .}$ \\
& - & - & - & - & -10. \\
& - & -55. & - & - & -50. \\
& - & -90. & - & - & -90. \\
& -170 & $\underline{-\mathbf{1 7 0 .}}$ & -170 & -170. & $\underline{\mathbf{- 1 7 0 .}}$
\end{tabular}

Four extreme cases are highlighted as shown in Table 1 in a bold font. They refer to a strain rate of 0.004 or $700 / \mathrm{s}$ and to a temperature of $+23^{\circ} \mathrm{C}$ (so-called Amb. Temp.) or $-170^{\circ} \mathrm{C}$ (so-called Cryo. Temp.).

\section{Results}

The stress-strain curves in compression from all the four extreme conditions are shown in Fig.8. When loaded in compression, the response can be characterized by an initial elastic regime, followed by a linear hardening regime and finally a regime of rapidly increasing stress due to the densification of the material [19, 25]. No brittle behaviour has been observed. The scatter in the results for each experimental condition can be seen. For each extreme experimental condition, one of the curves is taken as representative and shown in black and highlighted with $\mathrm{x}$ marks in Fig, 8 and plotted separately Fig.9 with error bars which represent the minimum and maximum stress of all of the data, every $10 \%$ in strain, large error bars are used for quasi-static strain rate of $0.004 / \mathrm{s}$.

\subsection{Strain rate sensitivity at ambient temperature}

Figs. (8, 9) show that at ambient temperature, the strain rate sensitivity of the out-of-plane compression stress of the birch plywood is huge. At a strain value of $3 \%$, the interpolated stress value is $11.8 \mathrm{MPa}$ at $0.004 / \mathrm{s}$ and as high as $20.8 \mathrm{MPa}$ at $700 / s$, which corresponds to a stress increase by a factor of $20.8 / 11.8 \approx 1.76$ for a strain rate multiplied by $1.75 \cdot 10^{3}$. This stress ratio $S_{r}$ is higher than the one we can calculate from the study published by Widehammar [30] in the case of the compression of an oven dried clear spruce wood in the radial direction, i.e. $S_{r}^{\text {Widehammar }} \approx 1.5$ for a strain rate multiplied by $1.25 \cdot 10^{3}$. However, our stress ratio is close to the one obtained by Eisenacher [14] in the case of the laterally confined compression of a $12 \%$ moisture content clear spruce wood in the direction perpendicular to the fibers $S_{r}^{\text {Eisenacher }} \approx 1.7$ for a strain rate multi- 
plied by $1.50 \cdot 10^{3}$. Eisenacher attributes this high stress ratio value to the lateral confinement he applied on the direction perpendicular to the fibers, leading to zero lateral strain in the radial or transverse directions, depending on the initial orientation. In our case, the out-of-plane compression of the plywood leads to a uniaxial straining of the specimen, with no lateral strain up to a compressive strain of 0.5 . This lateral confinement is obtained by the fact that (i.) two adjacent glued veneers have perpendicular fiber directions and (ii.) the veneer thickness to lateral dimensions ratio is about 0.05 , and (iii.) that the Young's modulus in the fiber direction is about 20 times the one in the lateral direction [22].

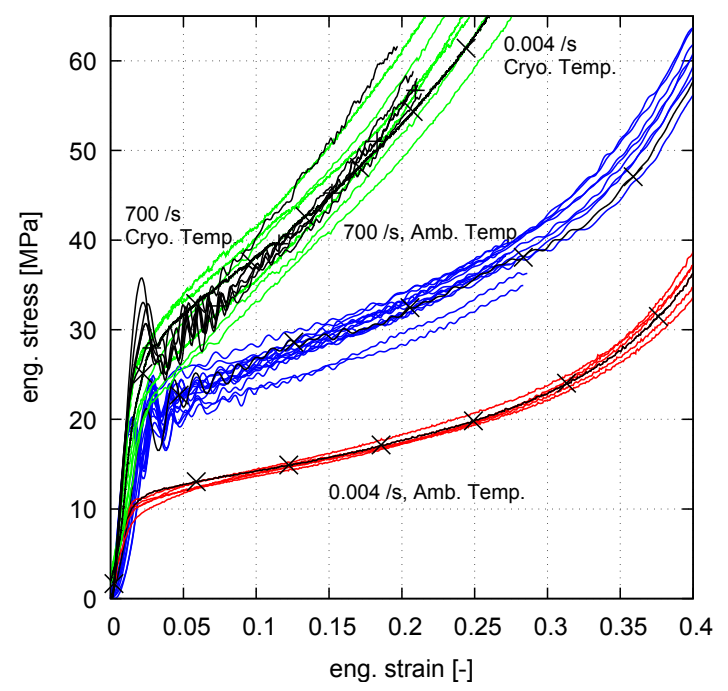

Figure 8: True stress versus true strain response during out-of-plane compression of a $8 \%$ moisture content $12 \mathrm{~mm}$ thick birch plywood specimen for the two different strain rates $(0.004 / \mathrm{s}, 700 / \mathrm{s})$ and the two temperatures $\left(+23^{\circ} \mathrm{C}\right.$, $\left.-170^{\circ} \mathrm{C}\right)$. The most representative curves are highlighted in black.

\subsection{Effect of temperature at the quasi-static strain rate}

Fig. 8 shows that for the quasi-static strain rate, the effect of cryogenic temperature is as high as predicted by Boller [8]. At a strain value of $3 \%$, the interpolated stress value is $11.8 \mathrm{MPa}$ at ambient temperature and $26 \mathrm{MPa}$ at $-170^{\circ} \mathrm{C}$, which corresponds to a stress increase by a factor $26 / 11.8 \approx 2.2$. 


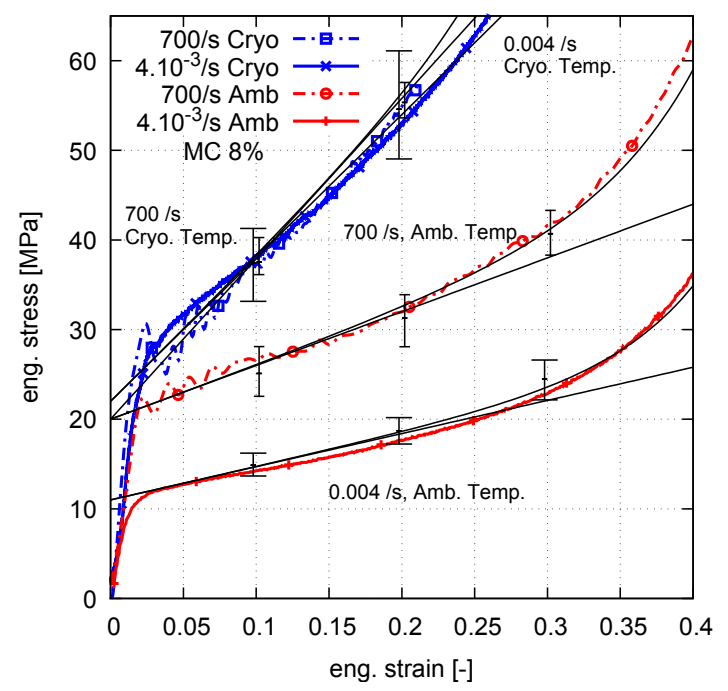

Figure 9: True stress versus true strain response during out-of-plane compression of a $8 \%$ moisture content $12 \mathrm{~mm}$ thick birch plywood specimen for the two different strain rates $(0.004 / \mathrm{s}, 700 / \mathrm{s})$ and the two temperatures $\left(+23^{\circ} \mathrm{C}\right.$, $\left.-170^{\circ} \mathrm{C}\right)$. The most representative curves are plotted along with a linear interpolation of the plateau behaviour. The errorbars represent the minimum and maximum stress of all of the data obtained on each condition.

\subsection{Strain rate sensitivity at cryogenic temperature}

If one focuses on the results presented in Fig. 8 at a cryogenic temperature of $-170^{\circ} \mathrm{C}$, it is clear that the stress strain curves obtained at the strain rate of $0.004 / s$ and $700 / s$ are not significantly different, and it can be concluded that the strain rate effect no longer exists at this cryogenic temperature. This result is confirmed by the cryogenic tests performed at $4.10^{-2} / \mathrm{s}$ and $4.10^{-1} / \mathrm{s}$.

\subsection{Stress strain curve model}

In order to quantify the evolution of the behaviour as a function of temperature and strain rate, an interpolation of the stress-strain curves has been conducted. Due to the significant increase in stress at sub-freezing temperatures, it has not been possible to lead all the experiments to the densification regime at the lowest temperatures or at highest strain rates. Thus, the interpolation has been conducted in two steps. (i.) A linear interpolation of the behaviour is performed for all the tests, and (ii.) an exponential interpolation of the densification regime is identified for each test performed up to densification, see 
Fig, 10, The linear model reads:

$$
\sigma=\sigma_{\text {int. }}^{h}+\sigma_{\text {mod. }}^{h} \cdot \varepsilon
$$

with $\sigma_{\text {int. }}^{h}$ the stress hardening intercept and $\sigma_{\text {mod. }}^{h}$ the hardening modulus of the linear interpolation.

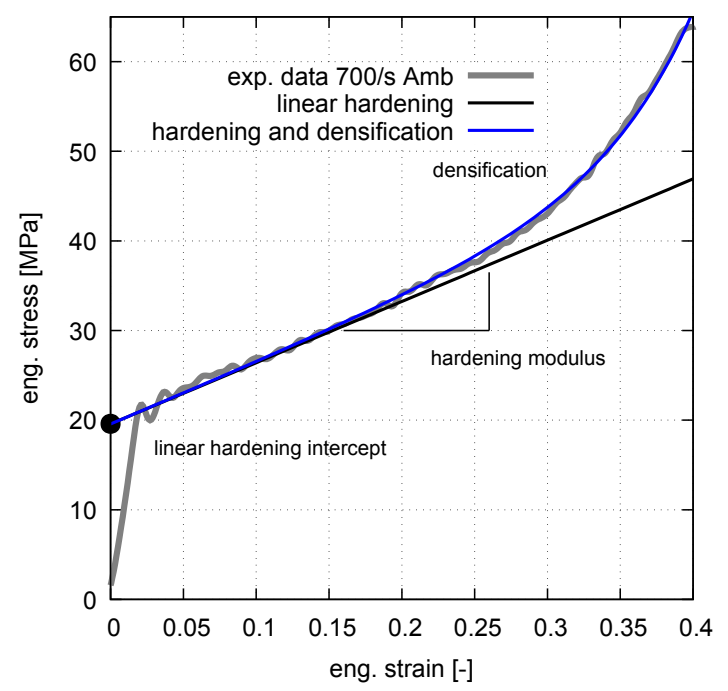

Figure 10: Stress versus strain experimental response and interpolation during out-of-plane compression of a $8 \%$ moisture content $12 \mathrm{~mm}$ thick birch plywood specimen.

In order to confine the linear interpolation to the pre-densification part of the hardening regime, a limited strain interval $([0.04 ; 0.2])$ was considered for each test. The lower limit corresponds to the minimum value at which equilibrium was obtained during SHPB experiments. Different values of the upper limit have been tested from $10 \%$ up to $25 \%$, and no significant evolution of the identified parameters was found up to a value of $22 \%$. We used an upper limit value of $20 \%$ in strain excepted for one test at high strain rate $(700 / \mathrm{s})$ and cryogenic temperature $\left(-170^{\circ} \mathrm{C}\right)$ condition for which the interpolation was performed using an upper limit of $19.5 \%$, its final strain. The minimum value of the square of the sample correlation coefficient among all the tested conditions is 0.95. Four interpolated behaviours are shown Fig.9 along with each representative curve and error bars.

The tests performed at a strain rate of $0.004 / \mathrm{s}$ and all the tests performed at ambient temperature represent eight experimental conditions Table 1. For each of these tests, if the final strain is greater than 0.3 ; an exponential interpolation Eq. 12 of the densification regime has been performed between $4 \%$ and 
final strain at maximum stress ; and the densification strain has been identified. The proposed exponential interpolation of the experimental stress versus engineering strain curve reads:

$$
\sigma=\sigma_{\text {int. }}^{h}+\left(\sigma_{\text {mod. }}^{h}-\sigma_{\text {mod. }}^{d} n_{\text {exp. }}^{d}\right) \cdot \varepsilon+\sigma_{\text {mod. }}^{d} \cdot\left(e^{n_{\text {exp. }}^{d}}-1 .\right)
$$

where $\sigma_{\text {mod. }}^{d}$ is the densification modulus and $n_{\text {exp. }}^{d}$ the densification exponent. With this definition, $\sigma_{\text {mod. }}^{h}$ is the initial hardening modulus value at zero strain. From a practical point of view, among all our identifications, the $\frac{\sigma_{\text {mod. }}^{h}}{\sigma_{\text {mod. }}^{d} n_{\text {exp. }}^{d}}$ ratio was found to be greater than 100 , and the influence of the $\sigma_{\text {mod. }}^{d} n_{\text {exp. }}^{d}$ term could be neglected in equation Eq.12. In the following, the hardening modulus refers to the $\sigma_{\text {mod. }}^{h}$ value. The densification strain $\varepsilon_{\text {dens. }}[6,28]$ was initially defined for foams and recently used in the case of wood impact by Wouts et al. [32]. The densification strain is defined as the strain at which the maximum value of the energy absorbing efficiency $\eta\left(\varepsilon_{a}\right)$ is reached, Eq. 13 , where $\varepsilon_{0}$ is the starting point of the linear hardening behaviour ; we used a constant value $\varepsilon_{0}=0.04$. This value is the third coefficient that can be gathered from these eight experimental conditions.

$$
\eta\left(\varepsilon_{a}\right)=\frac{\int_{\varepsilon_{0}}^{\varepsilon_{a}} \sigma(\varepsilon) d \varepsilon}{\sigma\left(\varepsilon_{a}\right)} \quad \text { and }\left.\quad \frac{d \eta\left(\varepsilon_{a}\right)}{d \varepsilon_{a}}\right|_{\varepsilon_{a}=\varepsilon_{\text {dens. }}}=0
$$

\subsection{Effect of temperature and strain rate on the linear harden- ing parameters}

Fig. 11, 12 show the evolution with temperature and strain rate (strain rate are in logscale) of the two linear interpolation parameters $\sigma_{i n t}^{h}$ and $\sigma_{\text {mod. }}^{h}$ of the stress versus strain hardening regime. Fig. 11 shows the evolution of the stress hardening intercept, the tick space represents a jump of $2 \mathrm{MPa}$ in stress. For the sake of simplicity, the vertical scale of the Fig. 12 plot is formatted in order to be able to compare the respective influence of the coefficients on the evolution of the stress: tick space of vertical axis corresponds to a jump of $2 \mathrm{MPa}$ of the stress plateau for a 0.1 strain increase.

Let recall that at cryogenic temperature of $-170^{\circ} \mathrm{C}$, there is no significant evolution of the two parameters with strain rate.

At ambient temperature, dashed lines Fig. 11, 12, the evolution of the hardening modulus is significant, but small compared to the evolution of the stress hardening intercept coefficient with strain rate.

At the quasi-static strain rate of $0.004 / s$, green curves Fig.(11, 12), the stress 
Caetano L, Grolleau V, Galpin B, Penin A, Capdeville J-D. High strain rate out-of-plane compression of birch plywood from ambient to cryogenic temperatures. Strain. 2018. https://doi.org/10.1111/str.12264

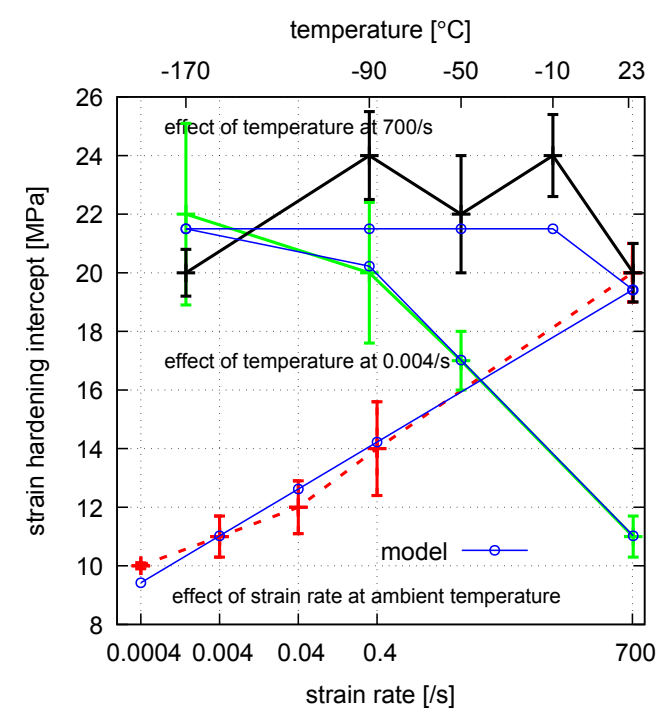

Figure 11: Hardening intercept coefficient $\sigma_{i n t .}^{h}$ evolution as a function of temperature (solid lines) and strain rate (dashed), the model prediction is shown in blue. Errorbars correspond to one standard deviation.

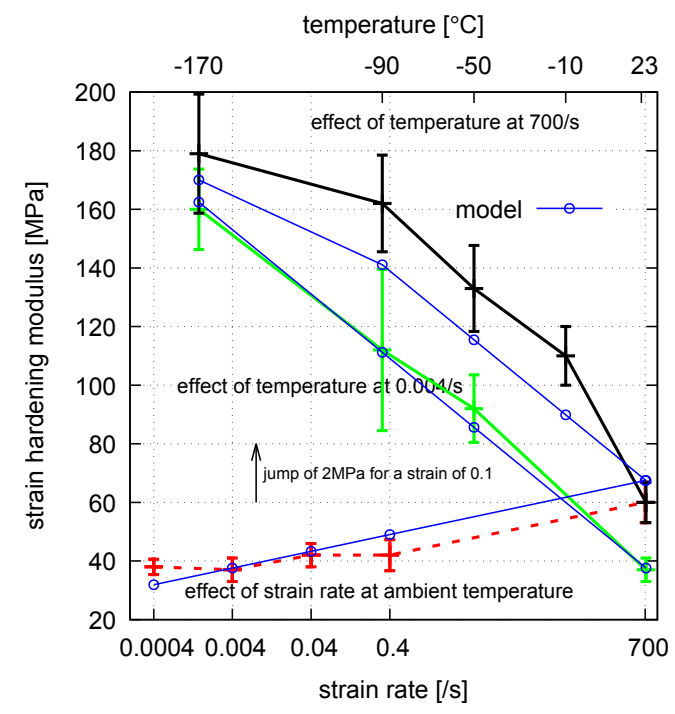

Figure 12: Hardening modulus coefficient $\sigma_{\text {mod. }}^{h}$ evolution as a function of temperature (solid lines) and strain rate (dashed), the model prediction is shown in blue. Errorbars correspond to one standard deviation.

hardening intercept coefficient and the hardening modulus coefficient are very sensitive to the temperature decrease, with a same order of influence on the stress value for a 0.1 strain. But, the evolution of the stress hardening intercept 
coefficient seems negligible for a temperature below $-90^{\circ} \mathrm{C}$. On the contrary, there is no saturation value for the slope coefficient in the considered temperature range.

At the high strain rate of $700 / s$, the evolution of the intercept coefficient seems negligible for a temperature below $-10^{\circ} \mathrm{C}$. Similarly, the evolution of the slope coefficient seems negligible for a temperature below $-100^{\circ} \mathrm{C}$.

The hardening intercept and hardening modulus evolutions with temperature and logarithmic strain rate can be also represented using a 3D plot given in Fig. 13 (left) and 14 (left) respectively. In these 3D plots, the saturation at highest strain rates and lowest temperatures is revealed, as well as the bi-linear evolution of each coefficient as a function of logarithmic strain rate $\left[s^{-1}\right]$ and temperature $[K]$. The evolution of each coefficient $C$ can be modelled using the following bilinear equation:

$$
C=\min \left[C_{S R}^{C} \cdot \log _{10}(\dot{\varepsilon})+C_{T}^{C} \cdot T+C_{c}^{C}, C_{\max }^{C}\right]
$$
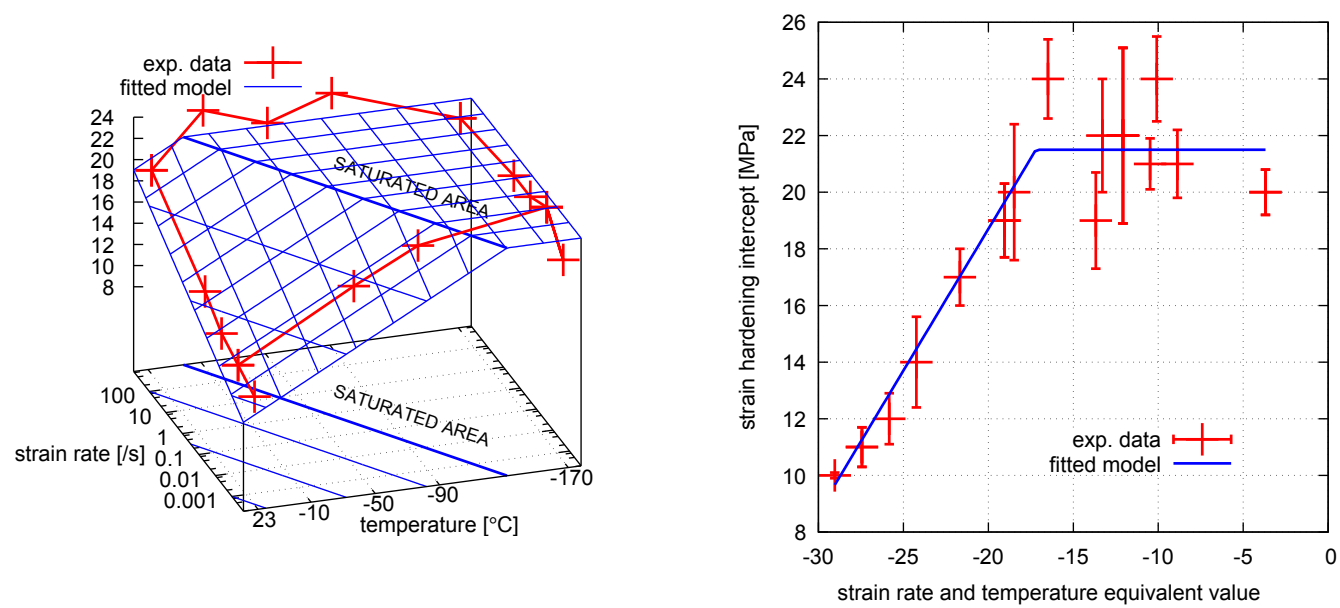

Figure 13: Left, 3D view of the hardening intercept $\sigma_{i n t .}^{h}$ evolution as a function of temperature and strain rate. Iso-values lines at specific $\sigma_{i n t .}^{h}$ value of 9.5, $13.5,17.5$ and $21.5 \mathrm{MPa}$ are plotted on base and surface. Right, evolution of the hardening intercept coefficient as a function of strain-rate-and-temperatureequivalent-value $T T E=C_{S R} \cdot \log _{10}(\dot{\varepsilon})+C_{T} \cdot T$. Errorbars correspond to one standard deviation of the coefficient.

where $C_{S R}^{C}, C_{T}^{C}, C_{c}^{C}$ are three constants involved in the bilinear evolution, and $C_{\text {max }}^{C}$ the saturated value of the considered coefficient, $\dot{\varepsilon}$ the strain rate $\left[s^{-1}\right]$ and $T$ the temperature $[K]$. The constants are identified using least square method and given Tab.2 along with the number of experimental conditions 

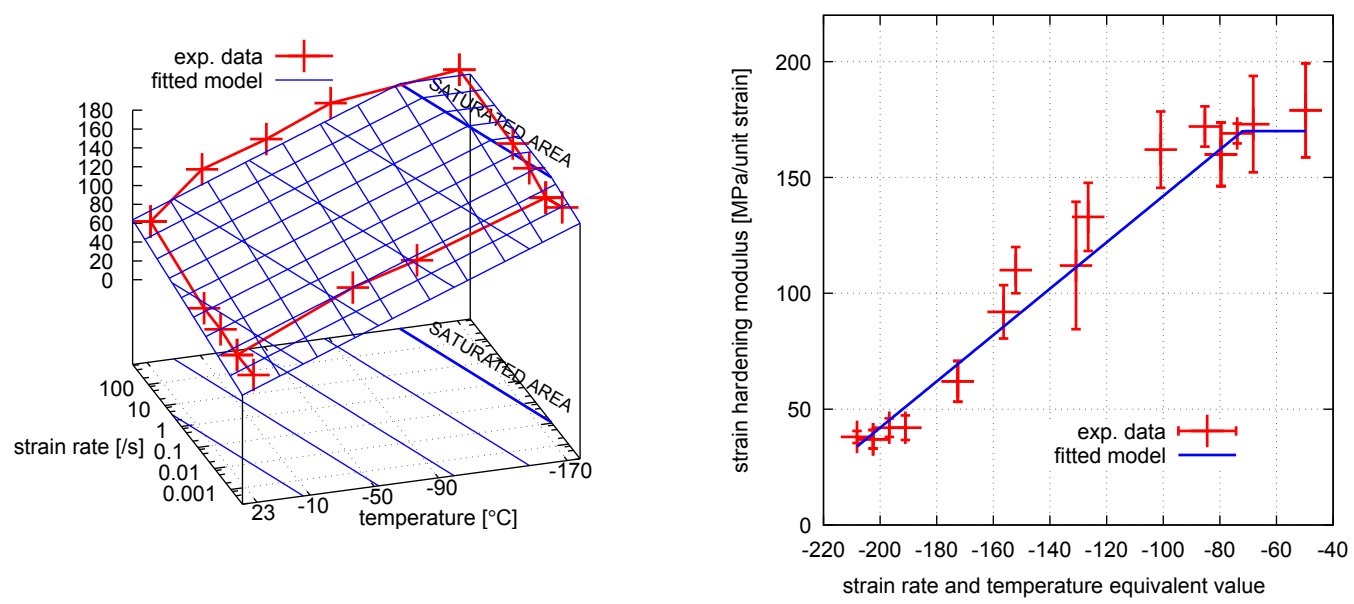

Figure 14: Left, 3D view of hardening modulus coefficient $\sigma_{\text {mod. }}^{h}$ evolution as a function of temperature and strain rate. Iso-values lines at specific $\sigma_{\text {mod. }}^{h}$ value of 50., 80., 110., 140. and 170.MPa are plotted on base and surface. Right, evolution of the hardening modulus coefficient as a function of strain-rate-andtemperature-equivalent-value $T T E=C_{S R} \cdot \log _{10}(\dot{\varepsilon})+C_{T} \cdot T$. Errorbars correspond to one standard deviation of the coefficient.

$N_{\text {cond }}$ involved in the identification. In the 3D plots, Fig.13(left) and $14($ left $)$, each isovalue corresponds to a specific value of the strain-rate-and-temperatureequivalent-value, or time and temperature equivalent value $T T E=C_{S R} \cdot \log _{10}(\dot{\varepsilon})+$ $C_{T} \cdot T$. Thus, to superimpose the stress strain curve at a temperature $T$ onto the curve at a reference temperature $T_{r e f}$ and strain rate $\dot{\varepsilon}_{r e f}$, the strain rate has to be scaled by a factor $a_{\left(T, T_{r e f}\right)}$ and reads $\log _{10}\left(a_{\left(T, T_{r e f}\right)}\right)=-C_{T}\left(T-T_{\text {ref }}\right) / C_{S R}$ using the standard WLF formulation [31,34].

Fig.13(right) and 14(right), the evolution of the hardening intercept and hardening modulus as function of their respective strain-rate-and-temperature-equivalent $T T E$ values are given. For each experimental condition defined by its temperature and strain rate, the mean values of the identified coefficient $\sigma_{i n t .}^{h}$ and $\sigma_{\text {mod. }}^{h}$. are plotted in red along with their corresponding one standard deviation errorbar calculated among a minimum of five repetitions. The identified bilinear model is plotted in blue solid line and a good agreement between the bilinear interpolation and experimental data is obtained. In the case of the hardening intercept coefficient, the difference between model and experimental data is lower than one standard deviation in the bilinear regime. In the case of the hardening modulus, the agreement of the bilinear model is lower. The maximum error reaches a value between one and two times the standard deviation for four experimental conditions, these are for the highest strain rate of $700 / \mathrm{s}$ 
and temperature of $-10^{\circ} \mathrm{C},-50^{\circ} \mathrm{C}$ and $-90^{\circ} \mathrm{C}$, and at the lowest strain rate of $0.0004 / s$ and temperature of $-170^{\circ} \mathrm{C}$. The orientation of the steepest descent direction of the bilinear model is normal to isovalues, which orientation is given by the slope of the isovalues in the strain rate and temperature plane, and reads $-C_{T}^{C} / C_{S R}^{C}$. This ratio value is 0.050 in the case of the hardening intercept but 0.11 in the case of the hardening modulus coefficient. As long as the identified bilinear model can be considered valid, this difference seems to show that the hardening intercept, which can be considered as an elastic limit, and the hardening modulus cannot be modelled using a unique time and temperature equivalent function.

Table 2: Identified constants of the bilinear models Eq.14 for each behaviour coefficients Eq. 12 .

\begin{tabular}{|c|c|c|c|c||c|} 
Coefficient & $C_{S R}$ & $C_{T}$ & $C_{c}$ & $C_{\max }$ & $N_{\text {cond }}$ \\
\hline$\sigma_{\text {int. }}^{h}[\mathrm{MPa}]$ & 1.6 & -0.080 & 38.7 & 21.5 & 15 \\
$\sigma_{\text {mod. }}^{h}[\mathrm{MPa}]$ & 5.7 & -0.64 & 242. & 170. & 15 \\
$\sigma_{\text {mod. }}^{\text {d }}[\mathrm{MPa}]$ & 0.0035 & -0.00032 & 0.11 & - & 8 \\
$n_{\text {exp. }}^{d}[-]$ & -0.39 & 0.012 & 14.43 & - & 8
\end{tabular}

\subsection{Effect of temperature and strain rate on the densification parameters}

Following the procedure used in the previous section, the experimental values of the densification modulus $\sigma_{m o d}^{d}$ are plotted Fig.15 as a function of strain rate and temperature ; Fig. 16 as a function of strain-rate-and-temperatureequivalent value. For this coefficient, the bilinear interpolation leads to an error between one and two standard deviations for three of the eight experimental conditions Fig 15 and 16 , but the linear tendency is confirmed by the linear regression coefficient value $r^{2}=0.94$ of the densification modulus versus strain-rate-and-temperature-equivalent-value interpolation. In the case of densification modulus, the slope of the isovalues in the strain rate and temperature plane $-C_{T}^{C} / C_{S R}^{C}$ is 0.091 , a value close to the one obtained for the hardening modulus. This suggests that these two parameters could be modelled using a unique time and temperature equivalent function.

The evolution of the densification exponent coefficient value $n_{\text {exp }}^{d}$ is plotted as a function of temperature and strain rate Fig.17; and as a function of strainrate-and-temperature-equivalent value Fig.18. The bilinear interpolation leads to an error value lower than one standard deviation Fig 17 and 18 , but the lin- 
Caetano L, Grolleau V, Galpin B, Penin A, Capdeville J-D. High strain rate out-of-plane compression of birch plywood from ambient to cryogenic temperatures. Strain. 2018. https://doi.org/10.1111/str.12264

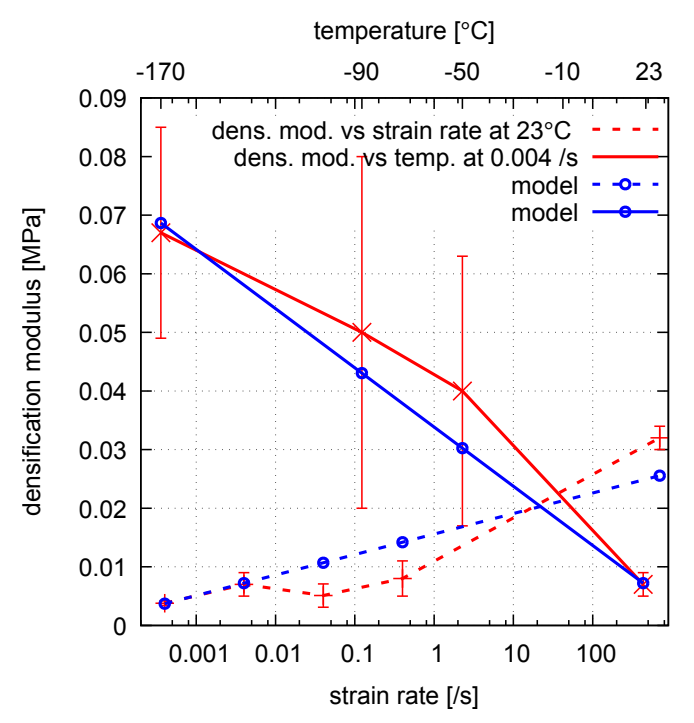

Figure 15: Temperature (solid lines) and strain rate (dashed) evolution of the densification modulus $\sigma_{\text {mod. }}^{d}$. Errorbars correspond to one standard deviation.

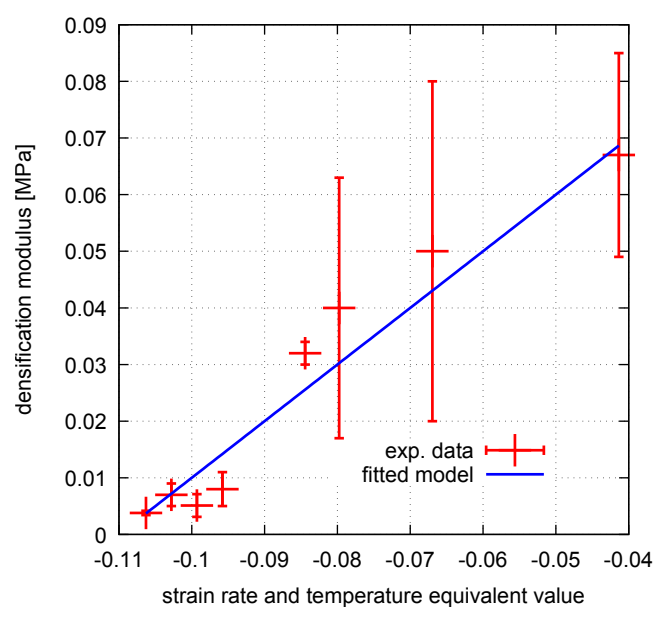

Figure 16: Evolution of densification modulus $\sigma_{m o d}^{d}$ as a function of strainrate-and-temperature-equivalent-value $T T E=C_{S R} \cdot \log _{10}(\dot{\varepsilon})+C_{T} \cdot T$. Errorbars correspond to one standard deviation of the coefficient.

ear tendency of the densification exponent versus strain-rate-and-temperatureequivalent-value is poor with a regression coefficient value of only $r^{2}=0.65$.

The densification strain Eq.13 has been identified for eight experimental conditions. The identification requires to choose a starting strain, commonly defined as the beginning of the so-called plateau behaviour of foam materials, 
Caetano L, Grolleau V, Galpin B, Penin A, Capdeville J-D. High strain rate out-of-plane compression of birch plywood from ambient to cryogenic temperatures. Strain. 2018. https://doi.org/10.1111/str.12264

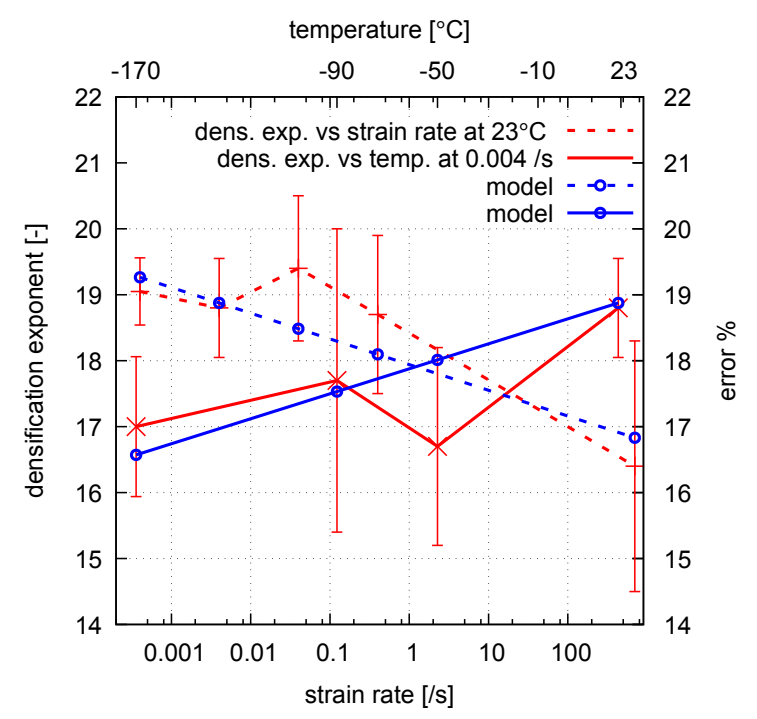

Figure 17: Temperature (solid lines) and strain rate (dashed) evolution of the densification exponent $n_{\text {exp. }}^{d}$. Errorbars correspond to one standard deviation.

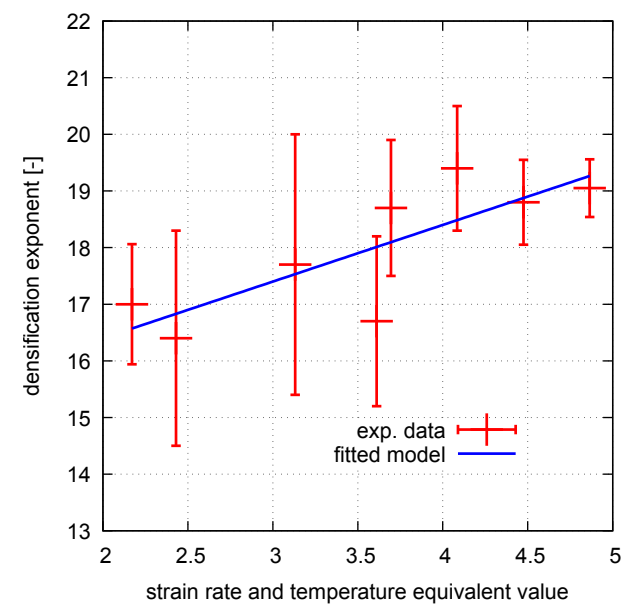

Figure 18: Evolution of densification exponent $n_{\text {exp. }}^{d}$ as a function of strainrate-and-temperature-equivalent-value $T T E=C_{S R} \cdot \log _{10}(\dot{\varepsilon})+C_{T} \cdot T$. Errorbars correspond to one standard deviation of the coefficient.

and in the range $[2 \%, 4 \%]$ in the case of plywood. But this point is not known at high strain rates, as equilibrium is only obtained for strains greater than $4 \%$ within the SHPB experiments performed. Moreover, using a starting point value of $2 \%$ or $6 \%$ leads to a difference in densification strain of only 0.005 for the four extreme conditions referenced in Table 1. We thus chose a constant 
starting strain value $\varepsilon_{0}=0.04$.

The evolution of the densification strain $\varepsilon_{\text {dens. }}$ is plotted as a function of temperature and strain rate Fig, 19. Whatever the experimental conditions, the densification strain value remains in the range [0.365, 0.381]. The evolution of the densification strain with temperature seems negligible, and only significant for a jump in strain rate by $10^{5}$ with jump in densification strain value about two time the standard deviation. The mean value of the densification strain over all the tested conditions is $\bar{\varepsilon}_{\text {dens. }}=0.37[-]$.

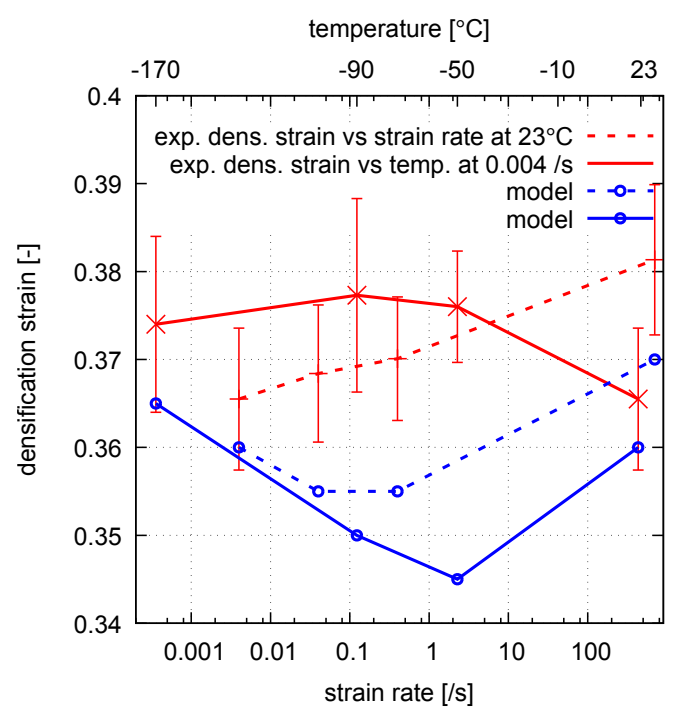

Figure 19: Temperature (solid lines) and strain rate (dashed) evolution of the densification strain $\varepsilon_{d}$. Errorbars represent one standard deviation of the value at the considered testing condition.

\subsection{Summary of the identified behaviour}

The behaviour equation Eq.12, and the coefficient equation Eq.14 led us to identify 14 constants given Table2. This behaviour can be used to estimate the stress versus strain curve and the densification strain at any temperature in the range $\left[25,-170^{\circ} \mathrm{C}\right]$ and strain rate in the range $[0.0004,700 / s]$. Representative stress strain curves from the experiments (black solid lines) are shown together with the corresponding results of the interpolation (thin black lines) for six experimental conditions in Fig.20. The ambient temperature tests are plotted in red for three different strain rates, and sub-zero tests are plotted in blue. The relative error in stress between interpolated behaviour and mean experimental values are lower than $7 \%$ for strains up to $30 \%$. This relative error can be as 
high as $15 \%$ after densification for a strain of $40 \%$. At a stress level of $100 \mathrm{MPa}$, the error in strain is lower than $7 \%$.

The experimental densification strains are plotted in red circles, and the one calculated from the interpolated behaviour are plotted with black circles Fig, 20 and blue solid lines (Fig.19). The maximum relative error is $8 \%$.

From an application point-of-view, at ambient temperature, the behaviour is strain rate sensitive, the stress jumps by a factor of 2. at $4 \%$ strain to 2.2 at $30 \%$ strain for a strain rate jump by a factor of $10^{5}$. In this case the absorbed energy at $30 \%$ strain is twice the quasi static one.

The behaviour is also highly temperature sensitive, and a drop of $-80^{\circ} \mathrm{C}$ from ambient temperature leads to a stress increase by 1.6 to 2.1 for strains of $4 \%$ and $30 \%$ respectively. At $-170^{\circ} \mathrm{C}$, the stress increase is saturated, whatever the strain rate, with jumps of 2. and 3.3. At cryogenic temperature, the absorbed energy at $30 \%$ strain is about 2.6 time the one at ambient temperature and quasi-static strain rate.

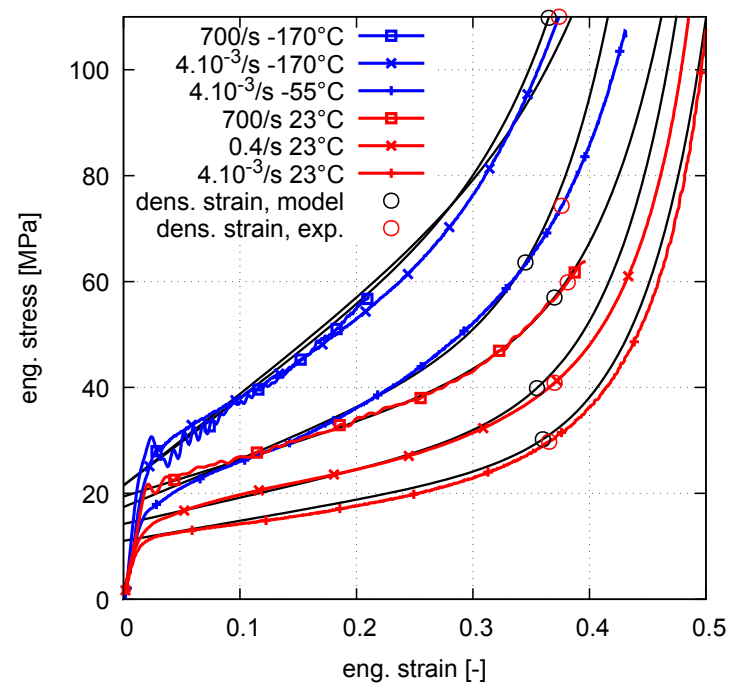

Figure 20: Experimental and interpolated (thin black lines) stress strain curves at various strain rates and temperatures. Experimental densification strains are plotted with red circles, the calculated ones are plotted with black circles.

\section{Conclusions}

The out-of-plane compression behaviour of $8 \%$ moisture content birch plywood under various experimental conditions has been studied. A large range of temperatures, from room temperature down to a cryogenic temperature of $-170^{\circ} \mathrm{C}$ 
Caetano L, Grolleau V, Galpin B, Penin A, Capdeville J-D. High strain rate out-of-plane compression of birch plywood from ambient to cryogenic temperatures. Strain. 2018. https://doi.org/10.1111/str.12264

have been explored. Quasi-static tests have been performed using a universal machine. We developed and validated a Split Hopkinson Pressure Bar procedure for high strain rate experiments at ambient and cryogenic temperatures. In this latter case, the specimen is cooled down together with two $40 \mathrm{~mm}$ long extensions made of the same material as the bars. Practical consideration of the SHPB test led us to a $28 \mathrm{~mm}$ diameter and $12 \mathrm{~mm}$ thick specimen. These dimensions were validated from a comparison to the one obtained using the EN789 standard. The analysis of the compression tests focused on the hardening behaviour of the stress versus strain curve during linear hardening and the following densification regime. The behaviour was fitted using a linear and a an exponential function of the strain, thanks to four coefficients, namely the stress hardening intercept, the hardening modulus, the densification modulus and the densification exponent. The evolution with temperature and strain rate of each coefficient has been studied and modelled using a bilinear function of the logarithmic strain rate and the temperature. A total of 14 constants have been identified. The following conclusions may be drawn from the experimental results:

- The compression stress increases significantly with decreasing temperature and increasing strain rate, but at the cryogenic temperature of $-170^{\circ} \mathrm{C}$, the strain rate sensitivity is negligible.

- At room temperature (resp. at a quasi-static strain rate of $0.004 / s$ ), the strain rate (resp. temperature) dependency of the hardening intercept, the hardening modulus and the densification modulus of the stress strain curve are significant. A saturation of the hardening intercept coefficient is observed for a temperatures below $-90^{\circ} \mathrm{C}$ and $-10^{\circ} \mathrm{C}$ for strain rates of $0.004 / s$ and $700 / s$ respectively. The same phenomenon is observed for the hardening modulus coefficient below $-100^{\circ} \mathrm{C}$ at a strain rate of $700 / \mathrm{s}$.

- The densification strain is found to be slightly strain rate sensitive, its value is 0.365 at a strain rate of $0.0004 / \mathrm{s}$ and 0.38 at a strain rate of $700 / \mathrm{s}$. The evolution with temperature seems to be not significant. The mean value is found to be 0.37 .

- Using the proposed interpolated model, the compression stress of the plywood can be interpolated at any temperature in the range $\left[25,-170^{\circ} \mathrm{C}\right]$ and strain rate in the range $[0.0004,700 / s]$. When compared to experimental data, the maximal error is about $7 \%$ up to a strain of $30 \%$. The densification strain can be also predicted with a maximum error of $8 \%$. 
Caetano L, Grolleau V, Galpin B, Penin A, Capdeville J-D. High strain rate out-of-plane compression of birch plywood from ambient to cryogenic temperatures. Strain. 2018. https://doi.org/10.1111/str.12264

\section{Aknowledgements}

We thank M. Hervé Bellegou for his technical support and all the employees of the study worksite at the Université de Bretagne Sud for their participation. Ms. Caetano was a recipient of a doctoral fellowship from the French Government. Study materials were funded by Gaz Transport and Technigaz Company. These supports are gratefully acknowledged.

\section{References}

[1] En 789: 2004 timber structures-test methods-determination of mechanical properties of wood based panels, 2004.

[2] Sloshing analysis of Ing membrane tanks, Technical Report 30.9, DNV, Det Norske Veritas, Veritasveien 1, NO-1322 Høvik, Norway, 2006.

[3] Gaztransport E technigaz company, [http://gtt.fr], 2016.

[4] C. Adalian and P. Morlier, Wood model for the dynamic behaviour of wood in multiaxial compression, Holz als Roh- und Werkstoff 60 (2002), 433-439 (English).

[5] A. Arswendy and T. Moan, Failure analysis of a liquid natural gas (lng) containment system bending failure of plywood component, Wood Material Science and Engineering 7 (2012), 30-40.

[6] M. Avalle, G. Belingardi, and R. Montanini, Characterization of polymeric structural foams under compressive impact loading by means of energy-absorption diagram, International Journal of Impact Engineering 25 (2001), no. 5, 455 -472.

[7] Nadir Ayrilmis, Umit Buyuksari, and Nusret As, Bending strength and modulus of elasticity of wood-based panels at cold and moderate temperatures, Cold Regions Science and Technology $63(2010 / 8 / /)$, no. 1-2, 40-43.

[8] Kenneth H Boller, Strength of wood at low temperatures. (Earl C. Myers and Norbert J Leinen, eds.), National academy of sciences, Washington, 1954.

[9] Bragov, A. and Lomunov, A. K., Dynamic properties of some wood species, J. Phys. IV France 07 (1997), C3-487-C3-492.

[10] Weinong Chen and Bo Song, Split hopkinson (kolsky) bar. design, testing and applications, Mechanical Engineering Series, Springer US, 2011.

[11] Min Sung Chun, Myung Hyun Kim, Wha Soo Kim, Sang Hyun Kim, and Jae Myung Lee, Experimental investigation on the impact behavior of membrane-type $\operatorname{lng}$ carrier insulation system, Journal of Loss Prevention in the Process Industries 22 (2009), no. 6, 901-907.

[12] Joseph R Davis, Tensile testing, ASM international, 2004.

[13] Garrett Drake, Michael Berry, and David Schroeder, Effect of cold temperatures on the shear behavior of glued laminated beams, Cold Regions Science and Technology 112 (2015/4//), 45-50. 
Caetano L, Grolleau V, Galpin B, Penin A, Capdeville J-D. High strain rate out-of-plane compression of birch plywood from ambient to cryogenic temperatures. Strain. 2018. https://doi.org/10.1111/str.12264

[14] G. Eisenacher, R. Scheidemann, M. Neumann, B. Droste, and H. Völzke, Dynamic crushing characteristics of spruce wood under large deformations, Wood Science and Technology 47 (2013September), 369-380.

[15] Handbook of finnish plywood, Finnish Forest Industries Federation, 2007.

[16] P. S. Follansbee and C. Frantz, Wave propagation in the split hopkinson pressure bar, Journal of Engineering Materials and Technology 105 (1983/01/01), no. 1, 61-66.

[17] Gérard Gary, David instruction, LMS, Palaiseau, France.

[18] C. Gerhards, Effect of moisture content and temperature on the mechanical properties of wood: An analysis of immediate effects, Wood and Fiber Science 14 (1982/01/01/), no. 1, 4-36.

[19] Lorna J Gibson and Michael F Ashby, Cellular solids: structure and properties, Cambridge university press, 1999.

[20] George T Gray, Classic split-hopkinson pressure bar testing., Materials Park, OH: ASM International, 2000. (2000), 462-476.

[21] Stefan Hiermaier, Structures under crash and impact, Springer US, 2008.

[22] Ross Robert J., Wood handbook: wood as an engineering material, Technical Report FPL- GTR190, U.S. Dept. of Agriculture, Forest Service, Forest Products Laboratory, 2010.

[23] Jeong-Hyeon Kim, Doo-Hwan Park, Chi-Seung Lee, Kwang-Jun Park, and Jae-Myung Lee, Effects of cryogenic thermal cycle and immersion on the mechanical characteristics of phenolresin bonded plywood, Cryogenics 72, Part 1 (2015), 90 -102.

[24] Franz Kollmann, The mechanical properties of wood of different moisture content within 200 degrees to +200 degrees c temperature range, Technical Report 984, National Advisory Committee for Aeronautics, Washington, DC, United States, 1941.

[25] S.R. Reid and C. Peng, Dynamic uniaxial crushing of wood, International Journal of Impact Engineering 19 (1997), $531-570$.

[26] R. M. Rowell (ed.), Handbook of wood chemistry and wood composites, Taylor\&Francis, 2005.

[27] W Sharpe (ed.), Handbook of experimental solid mechanics, Springer, 2008.

[28] P.J. Tan, S.R. Reid, J.J. Harrigan, Z. Zou, and S. Li, Dynamic compressive strength properties of aluminium foams. part i-experimental data and observations, Journal of the Mechanics and Physics of Solids 53 (2005), no. 10, $2174-2205$.

[29] B. Toson, P. Viot, and J.J. Pesqué, Finite element modeling of balsa wood structures under severe loadings, Engineering Structures 70 (2014), no. 0, 36 -52.

[30] Svante Widehammar, Stress-strain relationships for spruce wood: Influence of strain rate, moisture content and loading direction, Experimental Mechanics 44 (2004), 44-48. 10.1007/BF02427975.

[31] MP Wolcott, FA Kamke, and DA Dillard, Fundamentals of flakeboard manufacture: viscoelastic behavior of the wood component, Wood and Fiber Science 22 (2007), no. 4, 345-361.

[32] J Wouts, G Haugou, M Oudjene, D Coutellier, and H Morvan, Strain rate effects on the compressive response of wood and energy absorption capabilities-part a: Experimental investigations, Composite Structures 149 (2016), 315-328. 
Caetano L, Grolleau V, Galpin B, Penin A, Capdeville J-D. High strain rate out-of-plane compression of birch plywood from ambient to cryogenic temperatures. Strain. 2018.

[33] Han Zhao, Material behaviour characterisation using shpb techniques, tests and simulations, Computers \& Structures 81 (2003), no. 12, 1301 -1310. Advanced Computational Models and Techniques in Dynamics.

[34] J. Zhao, W. G. Knauss, and G. Ravichandran, Applicability of the time-temperature superposition principle in modeling dynamic response of a polyurea, Mechanics of Time-Dependent Materials 11 (2007Dec), no. 3, 289-308.

[35] Liyuan Zhao, Jinghui Jiang, Jianxiong Lu, and Tianyi Zhan, Flexural property of wood in low temperature environment, Cold Regions Science and Technology 116 (2015), 65 -69. 